number of students, partly because the instruction was rendered more thorough and efficient by the addition of laboratory and practical instruction in physics, mechanics, biology, and geology, and partly because South Kensington was more convenient for students than Jermyn Street or Oxford Street. The school was also rendered more useful by the fact that, after the transfer, a few teachers, and promising students who undertook to become teachers, were brought up to London to be trained. This system has been developed, and now from fifty to sixty teachers are annually trained in different branches of science. A system of short summer courses for teachers has also been organised, and this opportunity of improving themselves is highly valued by the teachers, about I 80 or 200 of whom are selected annually from some 500 or 600 applicants.

The affiliation of the School of Mines to the Normal School of Science in 1881 marked an era in the history of the institution and in the history of scientific work and education in this country. Students of all classes receive in these united schools systematic instruction in the various branches of physical science. The institution is primarily intended for the instruction of teachers and of students of the industrial classes selected by competition in the examinations of the Science and Art Department, but other students are admitted so far as there may be accommodation for them, on the payment of fees fixed at a scale sufficiently high to prevent undue competition with institutions which do not receive State aid.

All this is fully and clearly set forth in the "Calendar and General Directory," where also the reader will find ample details as to the Science Collections, the aid granted to local museums, the Committee on Solar Physics, the relation of the Government to scientific research, the Geological Survey, the Museum of Practical Geology, the Mining Record Office, and the scientific establishments of Edinburgh and Dublin.

In an article on "National Education in Science and Art," the Times on Monday last expressed a doubt whether, after all, any country can be much ahead of England in the number and excellence of its scientific institutions. The Times takes far too favourable a view of the relative position of the United Kingdom in such matters. Recent Consular reports have shown that our traders are being steadily beaten by German competitors in many great foreign markets; and the explanation is that, notwithstanding the progress we have made, our system of scientific instruction will not compare, in comprehensiveness and thoroughness, with that which has grown up in Germany. The Times, although unwilling to admit the superiority of our rivals, readily grants that as a nation we do not yet do enough for the promotion of science. It says :--

"When the general condition of popular artistic and scientific instruction is viewed, there can be no question that it is not in accordance with national responsibilities, whatever the average may be elsewhere. A primary result of the discovery is to abate some of the admiring content which study of the contents of the Science and Art Department's 'Calendar and Directory' is calculated to produce. To the Science and Art Department has been committed the task of imbuing the nation with those two extensive branches of human learning. The depreciatory estimates so freely offered in these days of the industrial attainments of the nation in each of them suggest either that the Department is not altogether equal to the enterprise, or that it has not been provided with the proper instruments."

The Times urges, with much force, that wealthy men have a magnificent opportunity of serving their country by following the example of the late Sir Joseph Whitworth in the endowment of scholarships, exhibitions, and prizes for students of science. With its remarks on this point all who are interested in science will agree; but it is necessary to point out that, however generous private persons may be, they cannot possibly meet the wants of England, with regard to science, in our time. This task can be properly undertaken only by the community as a whole, acting through its organ, the State. If it is not undertaken on the scale which circumstances have rendered necessary, we must be prepared to pay the penalty in diminished commerce and industry. On the other hand, the success which has attended our efforts in the right direction in the past ought to encourage us to make further sacrifices. There cannot be the slightest doubt as to the eagerness with which increased opportunities for scientific education of the highest order would be taken advantage of. At South Kensington there is not nearly room enough for the large number of students who annually seek admission, and like pressure will probably soon be experienced at many less important centres of scientific training. Here the Times speaks out strongly and well :-

"If the industrial classes in England be more or less deficient in taste and technical intelligence, it is from absence, not of natural aptitude, but of educational opportunities. Keenness of Continental competition may be far from an unmixed evil if it frighten Englishmen who have the ability into using it for the remedy of the shortcoming. Dulness and mental lethargy are in themselves evils, apart from the danger they cause of a loss of trade. A workman without insight into the meaning of the work he is doing, and with no perception of its real capabilities, is a mere bondsman to his occupation, instead of its master. While we suspect, as we have intimated, the existence of an exaggerated tendency to extol foreign technical training, the British mechanic will have no reason to regret the propensity, if it conduce to his equipment with the means of industrial enlightenment needed to convert his vocation from base drudgery into an art."

That the working classes are becoming alive to the necessity of an improved system of scientific and technical instruction may be inferred from the resolution on the subject which Mr. Howell proposes to move in the House of Commons. This resolution we print elsewhere, and our readers will agree with us in wishing $\mathrm{Mr}$. Howell all success in the admirable enterprise he has undertaken.

\section{THE PROGRESS OF ASTRONOMICAL PHOTOGRAPHY}

IN the Annuaire for the present year, published by the Bureau des Longitudes, is an important article by Admiral Mouchez, the Director of the Paris Observatory. The article is really a history of the various applications of photography used by astronomers up to the present time, and the history is very well done. The article contains many details relative to the work which has recently been going on in the Paris Observatory, which we think will be read with very general interest.

In the new instruments which the Brothers Henry have recently constructed at the Observatory, before a plate is taken the telescope is pointed approximately to a bright star, which is examined with an ordinary eye-piece, armed with a blue glass. In this way a slide can be placed very near the chemical focus, but in order to determine the focus exactly, an image of a star is made to run six or seven times along a very small plate at different marked distances inside and outside the focal point, as previously determined. An inspection by a magnifying glass of the different trails left by the star on the cliché shows which was the most exact chemical focus employed to produce them. This when once done really needs no repetition, but as a matter of fact the operation is repeated once a month.

Another point which the Brothers Henry have already settled is, that in the case of very many photographic plates of extreme sensitiveness the plates are practically 
useless unless they are prepared almost immediately before they are required, so that as a matter of fact very sensitive plates are now avoided.

Another limit to the sensitiveness which can be utilised is the diffused light proceeding from the atmosphere, either from the gas of a large town, as in Paris, or from the presence of the moon. Very sensitive plates are liable to be fogged even by diffused light in the case of very long exposures.

We have before referred to the arrangements employed for enabling the images of stars to be differentiated from any accidental spots or dots on the plate. The plate is practically exposed three times to the region of the heavens, with such a small variation of position, however, that the three images of the star on the plate appear as one to an observer who looks at it casually, and a magnifying glass is really necessary to discover the triple nature of the image. This method of working has been found to have advantages which were not anticipated in the first instance; thus, for the same total time of exposure the images of much more feeble stars are recorded with the three successive exposures than with one alone. This arises from the fact that the stars of the lower magnitudes, only being represented by very small points from $1 / 30$ to $1 / 40$ of a millimetre in diameter, would escape all observation by the naked eye, and would not be visible at all on paper copies ; while the three exposures give a larger image visible to the naked eye, and perceptible on a paper positive. Moreover, if a small planet is included in the region being photographed, the deformation of the small triangle would instantly betray its presence, even with an exposure of a quarter of an hour. Admiral Mouchez has calculated that a planet at twice the distance of Neptune would be easily recognised in three successive exposures of an hour each,- the motion of Neptune in half an hour quite destroying the triangle which it, like the stars, would make were it at rest.

The real and serious objection to the triple exposure is the wonderful patience and skill that are required to keep the instrument for three consecutive hours, without a moment's relapse, pointed rigorously towards the same spot in the sky. This is very trying work, and apt to overstrain those who perform it. Admiral Mouchez is alive to the fact that the way to obviate this difficulty is to increase the aperture of the object-glass, and this is what probably will be done before very long.

Some very interesting information is given regarding the microscopical appearances of the images of the stars seen on the negatives:- "The microscopical study of the clichés presents, moreover, much interest from many points of view, and the appearances of the images of the stars is so characteristic that it is impossible to confound them with accidental spots, as has been generally supposed; were this point of view alone regarded, it would perhaps be useless to multiply the exposures of the same plate. The stars appear on the plate, in fact, not under the simple form of a round spot of uniform black tint diminishing and becoming clearer as the star gets smaller, but as a mass of small, round, black points, very close together towards the centre for stars of the ten or twelve larger magnitudes, and more and more sprinkled, still retaining their blackness, for the fainter stars ; and at the extreme limit beyond those stars which give a definite and certain image, there still appear on the cliché some small groups of little points scattered sparsely, but evidently recording still fainter stars, the existence of which can only be suspected without any means of further confirmation.

"Unfortunately, whatever progress we may make in optics or in photography whatever, penetrating and sensitive power we may hope to give to our instruments, it is evident that we shall never succeed in seeing the most distant stars, and that at whatever limit we may arrive, there will always be beyond it an infinity of others lost in the profundity of the heavens which will always escape our knowledge, but it is by photography and the scientific study of negatives that we shall be able to go further than by any other means. From a chemical point of view also the microscopical examination of the stellar images will not be without interest, because it will help us to understand how the light acts upon the molecules of the insoluble salts of silver which are contained in the stratum of organic material which forms the sensitised plate. It is not, as I have already stated, in giving a uniform tint, more or less decided, according to the magnitude of the star, over the whole image, but really in decomposing a greater or less number of particles of salts of silver over this area, that the light works; so that we can define the image of a very feeble star as a resolvable nebula, and the others as insolvable nebulæ surrounded by a resolvable portion. I have never seen around any of these images the rings referred to by several astronomers, which have the appearance of diffraction rings seen in telescopes

"To establish the relationship between the scales of the optic and photographic magnitude of the stars, Bond has made a series of interesting experiments by varying the time of exposure and the aperture of the object-glass. These experiments have led him to an interesting result on the mode of action of light. He has found that a certain time elapsed before the action manifested itself at all, and then that it did so suddenly, ten or a dozen molecules of salts of silver in each superficial second of arc were attacked by the light; after this the number increased very rapidly according to the time of exposure. This mode of action seemed to him obscure and difficult to explain. But it seems to follow from these facts, and from the examination of our clichés, that in the manufacture of the bromide of silver, and the preparation of sensitive plates, it is of the highest importance to obtain the finest possible pulverisation of the salt."

As there is to be a Conference of Astronomers at Paris next Easter to discuss the whole question of astronomical photography, it is well that Admiral Mouchez and his staff are accumulating so many facts to help in the discussion.

METEOROLOGICAL CONDITIONS AT THE TIME OF THE ERUPTION OF MOUNT TARA WERA, NEW ZEALAND

$\mathrm{I}$ the Government Sanatorium at Rotorua there is a self-registering barometer kept by Dr. Ginders. This shows that at $9 \mathrm{a} . \mathrm{m}$. on June 9 , the atmospheric pressure was $29^{\prime} 30$ (at about I 000 feet above the sea). It decreased and reached its lowest point of $29^{\circ} 00$ at 4 p.m. on the gth. It then began to rise. At midnight it was $29^{\circ} 08$, and at I a.m. on the Ioth-just before the eruption-it was $29^{\circ}$ IO. This pressure was maintained all through the principal part of the eruption, after which the glass began to rise again, reaching $29^{.25}$ at noon on the roth. The curve, elsewhere smooth and even, shows from 3.30 a.m. to 6 a.m. a number of small oscillations which treble its thickness. None of these oscillations are recorded before and none after 6 a.m. on the 9 th, except a single one at 5 p.m. on Friday, the IIth. These oscillations are attributed to earthquakes, but, whatever may have been their cause, they certainly mark the outburst of Rotomahana and the crisis of the eruption.

Another barometer at Ohinemutu, belonging to $\mathrm{Mr}$. Edwards, of the Native Lands Court, read as follows :-

$$
\begin{aligned}
& \text { June 9, Io a.m...............29. } 30 \text { inches } \\
& \text { 4.30 p.m. ...........29.00 , } \\
& \text { ", 10, I.55 a.m. ............29.20, }
\end{aligned}
$$

The following is the rainfall at Rotorua :-

$$
\begin{gathered}
\text { June } 4 \ldots \ldots \ldots \ldots \ldots \ldots \ldots \ldots \ldots \ldots \ldots \ldots \ldots \ldots \ldots \ldots \ldots \ldots \ldots \\
, y
\end{gathered}
$$

